\title{
Research of French Negative Way Teaching
}

\author{
Li Yang ${ }^{1}$ \\ ${ }^{1}$ Xi'an International University, Xi'an, China, 710077 \\ 346591653@163.com
}

KEYWORDS: French; Negative Practices; Concept Definition; Context

\begin{abstract}
French negation ways is various, including absolute negation of all negation, negation and relative partial denial, double negation and affirmation, implicit denial and negation general, there are certain similarities than negative way, there are also some differences, students will more easily both on the negative approach of the confusion. The concept is similar to the negative approach of the above groups were analyzed, and examples of the concept of individual negative practices, to analyze different aspects of the relationship between the negative approach, semantic, etc., to accurately define the different concepts of negative tactics, and made statements to grasp real context determined negative content, extent and effect of the expression of the rational use of negative tactics negative practices.
\end{abstract}

\section{Introduction}

Negative approach is a common way to use French daily communication, even in the meaning of the expression affirmative sentences the French people are accustomed to using negative tactics expressed directly using less affirmative sentence habits. For example the expression of cheap goods prices, the use of negative sentence "Ce n'est pas cher" (this thing is not expensive) to express. Another example is the expression of a person is not handsome, the French usually negative affirmative sentence "Il n'est pas beau" direct expression of a person very plain, without the use of affirmative sentence "Il est laid". French people is belong to common rhetorical devices, subtle expression of affirmation through negation sentence meaning, and therefore knows the negative approach of great significance. But the French in the large number of negative words, from the expression of the concept of point of view, is divided into absolute negation negative words, relative negation, double negation, negation and other hidden forms of negation, there are certain similarities in different negative forms, the use of easy to confuse negative, resulting in students using negative tactics wrong. Therefore, this negation of the French approach to analyze and differentiate negative charge concepts sentences start to improve students' ability to properly use the negative sentence.

\section{Distinguish Different Concepts of Negative Way Teaching}

\section{A. Absolute Negation and All Negative Conceptual Distinction Teaching}

In China all kinds of French textbooks, absolutely negative is always important and difficult teaching. French absolute negation refers to the "ne ...... pas", "ne ...... plus" and other negative way, use the preposition "de" instead of an indefinite or definite article in front part of the direct object. In stressed that such a negative word before, need to meet the "no word", "direct object," "section 
article" three conditions, or to meet the "no word", "direct object," "indefinite article" three conditions. Based on the three conditions of absolute negation, absolute negation can be summarized as the meaning of the expression "direct object number zero." In about three conversations Case: (1) Tu as une voiture? Non, je n'ai pas de voiture (car number zero); (2) Vous faites du sport? Nonje ne fais jamais de sport (I exercise zero); (3) Elle a de l'argent? Non, the number (money is zero).

As it can be seen from the above three negative way, after each verb contain a direct object, no sentence adverbial component. The negative way of expression and Chinese expression is similar to the expression of a logical sequence substantially the same sentence. Therefore, the above three negative ways respectively translated as: "I have no car," "I never sport," "I have no money."

Introducing the concept of absolute denial must be absolutely negative and all the negative distinction. According to the definition of French scientists, all the negative is the use of negative words or deny an expression of the whole structure of the sentence were negative, that is the whole sentence appears all actions or things, the use of negative words or negative structure negation. For example, in the following two sentences, (1) Il vient? Non, il ne vient pas (he does not come); (2) Il fait chaud? Non, il ne fait pas chaud (today the weather is not hot) from all the negative sentence and absolute negation sentence, formula translation can be seen all the negative and absolutely negative way that there is a common denominator, the absolute negation of all negation and adverbial does not apply. The difference between the two is that the two different negative content, both for all the negative and negative predicate verb, direct object can also be used in negative. The absolute negation only used in negative direct object. Although modern French No absolute negation of all negation and make a clear definition, there is no clear theoretical analysis and comparison of the two carried out only in accordance with the sentence expression of semantic distinction, and all the negative coverage in the absolute negation .

\section{B. Negation and Relative Partial Denial Conceptual Distinction Teaching}

French presences absolutely negative way, so there is relatively negative. From a logical point of view, the absolute and relative negation two practices correspond to the inherent logic belongs relationship. In actual use, a relatively negative way can be used to negate a variety of sentence elements, such as for negative object of the sentence, qualifiers, adverbial sentence elements, but some can not be used to deny the negative predicate verb. In some cases, relatively negative can also be called partial denial, partial denial and thus relatively formal title belongs differences, the essence of the difference between the two does not exist. In daily communication, some negative practices using higher frequencies, are active negative expression. For example negative object: Je n'aime pas le cours d'anglais (I do not like English class); for negative time adverbial: Je ne travaille pas le samedi soir Saturday night I do not work); for adverbial negation Location: Je ne travaille pas en France (French I do not work); used in negative ways adverbial: Tu ne viens pas en voiture (you do not come by car). Examples can be seen from the above, the relative negative (negative part) can be used to negate all the components of the sentence other than the verb.

\section{Double Negation and Affirmation Conceptual Distinction Teaching}

In general, the double negative expression and affirmation of the same meaning, but this generalization is a brief summary of a double negative or one-sided generalizations. In fact, the double negative expression is certainly not exactly the same meaning, semantic two expressions there are some differences. For example, about three statements: (1) "Il n'a pas fait ce travail sabs peine" and "Il a fait ce travail avec peine"; (2) "Ce n'est pas rien" and "C'est quelque chose "; (3)" Vous pouvez finir toutca avant inuit Ce n'est pas impossible "and" C'est possible". 
From Examples (1) can be seen, the use of two negative words sentence expression double negative meaning, such as "ne ...... pas" and "sans", double negative effect of expression is certainly better than direct expression, showing double negative tone more intense level, passing out information directly to the recipient "no ado, do not spend effort, he simply impossible to live this" message. If the direct use of affirmative sentence "Il a fait ce travail avec peine" expression statement can only reflect a deeper meaning, "he has overcome some difficulties after the completion of this alive." Compared with the double negative expression, direct expression is certainly more feeble. Therefore, from the point of view semantic effect semantic double negation expressed more strongly, giving a rich imagination. Then in the sentence (2), and also used a double negative sentence, the sentence meaning "you can do all the things in it before midnight", with echoes of the answer is "it is impossible", " it is possible to do, "the. As can be seen from the statement of expression, it can better highlight the use of double negatives after "getting things done" hardships, lack of motivation to do things the situation. The direct use of affirmative sentence can reflect the positive attitude of the speaker: through a determined effort can be done. Therefore, the above expression of the double negative and positive effects can be seen in the sentence, the double negative effect of language expression is weaker than direct affirmation.

\section{Implied Negation and Negative General Conceptual Distinction Teaching}

Implicit deny published by means of word formation negation hair, both plus some prefix before sentence nouns, adjectives, adverbs and other words or ingredients used to express negative meaning, rather than using "ne ...... pas," "ne ...... plus "and other negative adverbs express negative meaning. In the French expression, there are many types of speech "hidden negative word" for the expression of negative, negative words and hidden diversity. For example, the expression is not active, inactive noun "activité-inactivité", impure (Pureté-impureté); means "not normal" and "impossible" adjective "normal-anormal", "Possible-impossible"; that " so unbalanced "and" not to recognize the "verb" équilibre-déséquilibrer "," avouer-désavouer ". In practice, the implicit negation and general negative meaning, although significant differences do not exist, but there is a significant difference between the two tone. For example, about three sentences: (1) Ce n'est pas normal (c'est anormal); (2) Ce n'est pas un siège confortable (c'est un siege inconfortable); (3) Il n'a pas avoue ses écrits (Il a désavoue ses écrits). Examples of these three general affirmative sentence and negative sentence expression meaning there is no difference, but the use of derivatives, a rear recessive negative, the negative tone of the sentence more intense. Examples such as (1) the "anormal" word, meaning not normal, general use in the negative drama "This is not normal," the expression, "anormal" expressed not normal with a more courageous, positive and strong tone, Examples (2) and (3) the implicit denial exhibited more intense tone.

\section{French Negative Way Teaching Suggestions Based on Correct Understanding of Context}

Before differentiate specific types of negative way, not a negative way to distinguish between the different meanings according to whether it is absolute or relative negation theory belongs. Negative way theory is the notion of belonging to linguists in theory proposed, easily distinguish the different negative ways, the term did not fully consider the context of the theory of language change in the exchange, and the context of changes in the use of the negative wealth effect of sentence have a great influence. Therefore, in actual use negative tactics, the need to deny the content, use negative tactics to achieve the expected effect, etc., and ultimately determine the negative practices. For example, the following three examples: (1) Tu as cours ce soir? Non, je n'ai pas de cours ce soir; (2) Tu vas souvent en France? Non, Je ne vais pas souvent en France; (3) Est-il ton patron? Non, il n'est 
pas mon patron. From the theoretical point of view, the meaning of the above three sentences are: "No, I have a class tonight," "I do not often go to France," "it's not my boss." However, based on the actual context „, intonation and tone changes in the severity of the sentence, the sentence may be more ambiguous. Examples (1) Main + that + direct object + adverbial structure, the content of the performance of the sentence structure is different focus, easily lead to ambiguity. Sentences can be expressed as "Tonight I can not, but I have other things," can also be expressed as "I do not have class tonight, but tomorrow night," or "Tonight I have no classes and others." Examples (2) may be expression meaning "I do not often go to France, and occasionally go twice a year" and also may be "Although I do not often go to France, but I often go to other countries"; Examples (3) is also possible to express " he is not the boss, he is our boss "semantics or" he is not my boss but colleagues "semantics, it may be" he's not my boss, others are my boss "significance. Although sense, the three caught expressing "He's not my boss," meaning, but there is a big difference between the actual semantics.

As can be seen from the above three sentences, to deny the right to master the correct way to behave the way, you must understand the extent of the negative practices to be met, we want to express semantic effect. Therefore, before using negative tactics, not only need to look at the type of negative words, but also requires a combination of dialogue in which both sides locale correctly distinguish dialogue locale help guide the proper use negative methods of expression, will also help from a macro or overall perspective of discourse to make the right judgment.

\section{Conclusion}

All in all, the French expression more negative way, the existence of similarities and differences between different manifestations, negative tactics teaching, teachers should be combined with the specific context of the boot, allow students to choose the best negative depending on the context in which the dialogue expression techniques to achieve the best effect of expression.

\section{Acknowledgements}

Proj: Shaanxi Province Education and Science" "Second Five" Project, Foreign Language Teaching Reform and Practice Research on Private Universities, NO. SGH140875

\section{REFERENCE:}

[1] Zhang Defu. French "Absolute Negation" Research and "Relatively Negative" Issues [J]. Learning French, 2014,02: 30-35.

[2] Li Yi. On Semantic Direction and Teaching Practice in French Negation Structure [J]. Popular Science, 2012, 03: 166-167+165.

[3] Zhang Yuan. Chinese Translation Method Negative [J]. Nanchang College of Education, 2011,08: 170+172.

[4] Zheng Zhenai. Absolutely Negative Sentences in French and Comparative Sentences Relatively Negative [J]. Shenyang Agricultural University (Social Science Edition), 2004, 04: 444-445.

[5] Pu Yaqin. Common Mistakes French Negative Sentences [J]. Learning French, 2006,02: 21-24. 